\title{
Sorption of Palladium by Carbon Sorbents from Aqueous Solutions
}

\author{
Anna O. Eremina ${ }^{a}$, Valentina V. Golovina ${ }^{a}$, \\ Anatoly A. Sobolev a and Nikolai V. Chesnokov ${ }^{\mathrm{a}, \mathrm{b} *}$ \\ anstitute of Chemistry and Chemical Technology SB RAS \\ 50-24 Academgorodok, Krasnoyarsk, 660036, Russia \\ ${ }^{b}$ Krasnoyarsk Scientific Center SB RAS \\ Academgorodok, Krasnoyarsk, 660036, Russia
}

Received 10.10.2015, received in revised form 29.10.2015, accepted 18.11.2015

Carbon sorbents from aspen-wood charcoal, mixed birch wood and aspen wood wastes and Siberian larch bark have been produced by pyrolysis and air-steam activation. Results of study of palladium adsorption from aqueous hydrochloric solutions at a concentration of 50-1100 mg/l by obtained active carbons are presented. The degree of palladium isolation was $95-99 \%$ at initial palladium concentration below $500 \mathrm{mg} / \mathrm{l}$ and consumption of sorbents $10 \mathrm{~kg} / \mathrm{m}^{3}$.

Keywords: carbon sorbent, sorption, palladium.

DOI: $10.17516 / 1998-2836-2015-8-4-541-549$.

(C) Siberian Federal University. All rights reserved

* Corresponding author E-mail address: cnv@icct.ru 


\title{
Сорбционное извлечение палладия \\ углеродными сорбентами из водных растворов
}

\author{
А.О. Еремина ${ }^{a}$ В.В. Головина ${ }^{a}$, \\ А.А. Соболев ${ }^{\mathrm{a}}$, Н.В. Чесноков ${ }^{\mathrm{a}, \boldsymbol{0}}$ \\ ${ }^{a}$ Институт химии и химической технологии СО РАН \\ Россия, 660036, Красноярск, Академгородок, 50-24 \\ ${ }^{6}$ Красноярский научный цеентр СО РАН \\ Россия, 660036, Красноярск, Академгородок, 50
}

Методами пиролиза и парогазовой активации получены углеродные сорбенты из углясыриа древесины осины, смешанных древесных отходов лесозаготовок березовой и осиновой древесины, а также из коры лиственницы сибирской. Приведены результаты исследований сорбчии палладия из водных солянокислых растворов (с концентрацией 50-1100 мг/л) полученными сорбентами. При исходных конщентрациях палладия до 500 мг/л и расходе

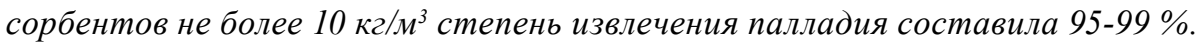

Ключевые слова: углеродный сорбент, сорбиия, палладий.

\section{Введение}

Повышенный интерес промышленных предприятий к поиску методов извлечения благородных металлов из различных водных сред обусловлен ростом стоимости и потребления благородных металлов, вынуждающих проводить их доизвлечение из сточных вод, отработанных гальванических и промывных растворов. Основными методами по-прежнему остаются электролиз и ионный обмен: разрабатываются новые конструкции электролизеров, ведутся работы по поиску и созданию селективных ионообменных смол и т.д. [1-4].

Эффективным методом извлечения металлов из водных сред является также сорбционный метод с применением пористых материалов естественного и искусственного происхождения [5-8]. Чаще других для этих целей применяют активные угли. Они гидрофобны, и энергия адсорбционного взаимодействия их поверхности с молекулами воды ниже энергии взаимодействия с молекулами большинства неорганических и органических веществ [9].

В настоящее время общие объемы производства активного угля в мире составляют 1 млн 250 тыс. т и характеризуются ежегодным приростом объема производства около 5 \% [10]. В 2000 г. в России по разным оценкам было произведено 10-12 тыс. т активных углей, а в 2008 г. всего лишь 4-5 тыс. т. Сегодня в среднем производится 2,5-3 тыс. т в год. РФ испытывает недостаток в промышленных активных углях, который компенсирует импортными поставками из зарубежа. В настоящее время РФ закупает от 19 до 26 тыс. т/год активных углей, причем закупки имеют тенденцию к росту [11].

Для получения различных марок активных углей в мире постоянно ведется поиск низкозольного углеродсодержащего сырья. Перспективным сырьем для получения углеродных сор- 
бентов являются возобновляемые лигноцеллюлозные материалы растительного происхождения, в частности древесные отходы. В литературе имеются достаточно обширные сведения о получении активных углей из некондиционной древесины, лесосечных отходов, отходов деревообработки, а также применении полученных активных углей для процессов очистки водных сред от ряда органических и неорганических примесей [12-17].

Целью настоящей работы стало изучение физико-химических и адсорбционных свойств (по отношению к ионам Pd (II)) углеродных сорбентов, полученных из угля-сырца (из древесины осины, из смешанных лесосечных отходов березовой и осиновой древесины) и коры лиственницы сибирской.

\section{Экспериментальная часть}

В качестве сырья для получения углеродных сорбентов использовали уголь-сырец, полученный из смешанных древесных отходов, уголь-сырец из древесины осины и кору лиственницы сибирской.

Уголь-сырец из смешанных древесных отходов лесозаготовок березовой и осиновой древесины (ветки, сучья, вершинник) имел влажность 5,0 \%, зольность 1,8 \%, был получен на установке УВП-5Б в районе р. Бирюсы Красноярского края. Уголь-сырец из смешанных древесных отходов подвергали парогазовой активации в реакторе с кипящим слоем [18] при температуре $850{ }^{\circ} \mathrm{C}$; время активации составляло 0,5 ч; концентрация кислорода и пара в парогазовой смеси - 5 и 35 об. \% соответственно. От суммарного продукта активации отделяли пыль - частицы размером менее 0,1 мм. Для испытаний использовали продукт активации древесного угля-сырца с размером частиц 0,1-1,0 мм (БОАУ-1).

Уголь-сырец из древесины осины имел влажность 4,3 \% мас., зольность 1,6 \%; был получен в лабораторной щелевидной реторте из жаропрочной стали в Сибирском государственном технологическом университете (г. Красноярск) [19]. Активацию угля-сырца из древесины осины проводили в реакторе со стационарным слоем. Реактор выполнен из нержавеющей стали, имеет внутренний диаметр 43 мм, длину 500 мм. Активацию осуществляли при температуре $800{ }^{\circ} \mathrm{C}$ в течение 0,5 ч при подаче смеси водяного пара (50 об. \%) и кислорода (1 об. \%, остальное - азот). После отделения пыли (класса крупности менее 0,1 мм) продукт активации (ОСУ-3) использовали для испытаний.

Кору лиственницы сибирской отбирали на специально отведенном участке в окрестностях Красноярска (использовали кору свежесрубленных деревьев на высоте не менее 1 м от комля), высушивали до воздушно-сухого состояния, измельчали, отбирали класс крупности от 0,5 до 5,0 мм. Термическую обработку коры проводили в описанном выше реакторе. Пиролиз коры шёл в токе азота с подъемом температуры до $650{ }^{\circ} \mathrm{C}$ и выдержкой в течение 0,5 ч. Активацию карбонизованной коры осуществляли в вышеописанных условиях, как и активацию углясырца из древесины осины. Продукт активации (ЛКАУ-2) использовали для адсорбционных исследований.

Физико-химические и адсорбционные свойства углеродных сорбентов определяли по известным методикам [20, 21]. Объем пор вычисляли методом объемной адсорбции паров азота в вакуумной адсорбционной установке на приборе ASAP.2400.VI.00 при температуре жидкого

$$
-543-
$$


азота (расчет проводили по десорбционной ветви изотермы методом Брукгоффа де Бура $[22,23])$.

Непосредственно перед испытанием углеродные сорбенты подсушивали при температуре $105-110{ }^{\circ} \mathrm{C}$ в течение 2 ч, после охлаждения в эксикаторе над осушителем взвешивали в бюксах с точностью до 0,2 мг (масса образца 0,1 г). Затем для насыщения углеродных сорбентов парами воды помещали в емкость с влажностью воздуха 98-99 \% (над насыщенным раствором карбоната натрия) при температуре $40{ }^{\circ} \mathrm{C}$ [24]. Подготовленные таким образом образцы углеродных сорбентов переносили в колбы с притертыми пробками с 10 мл водных растворов палладия. Встряхивали с малой интенсивностью в течение 48 ч. Водный раствор отделяли центрифугированием, определяли остаточное содержание палладия в растворе фотометрическим методом с нитрозо-R-солью [25].

Исходную концентрацию палладия в водных растворах варьировали в пределах от 50 до 1100 мг/л. Для приготовления водных растворов использовали хлорид палладия марки «ч».

\section{Результаты и обсуждение}

Основные физико-химические и адсорбционные свойства полученных углеродных сорбентов приведены в табл. 1. Образцы углеродных сорбентов имеют низкую зольность $(3,8$ $5,8 \%$; развитую пористую структуру: объем пор от 0,54 до $2,6 \mathrm{~cm}^{3} / \Gamma$, удельную поверхность 359-571 м²/г; достаточно высокую адсорбционную активность по йоду (51-84 \%).

На рис. 1 приведены изотермы адсорбции палладия из водных растворов на углеродных сорбентах. Для сравнения представлена также изотерма адсорбции палладия на промышленном сорбенте РС (Сербия), полученном из сливовых косточек, имеющем суммарный объем пор $1,0 \mathrm{~cm}^{3} / \Gamma$, долю объема микропор в суммарном объеме пор, равную 0,35 , удельную поверхность $930 \mathrm{M}^{2} / \Gamma$.

При одинаковой равновесной концентрации палладия в растворе углеродные сорбенты значительно различаются по величинам адсорбции. В области равновесных концентраций палладия до 8-10 мг/л наибольшую крутизну имеют изотермы сорбции палладия на углерод-

Таблица 1. Физико-химические свойства углеродных сорбентов

\begin{tabular}{|l|c|c|c|}
\hline \multicolumn{1}{|c|}{ Показатели } & \multicolumn{3}{c|}{ Сорбенты } \\
\cline { 2 - 4 } & БОАУ-1 & ЛКАУ-2 ${ }^{2}$ & OСУ-3 $^{3}$ \\
\hline Влажность, мас.\% & 0,5 & 7,2 & 0,7 \\
Зольность, мас.\% & 3,8 & 5,8 & 3,9 \\
Насыпная плотность, г/дм ${ }^{3}$ & 275 & 110 & 123 \\
Суммарный объем пор (по БЭТ), см $3 / \Gamma$ & 1,98 & 2,60 & 0,54 \\
Объем микропор (по БЭТ), см $/ \Gamma$ & 0,42 & 0,33 & 0,24 \\
Доля объема микропор в суммарном объеме пор & 0,21 & 0,13 & 0,44 \\
Удельная поверхность (по БЭТ), м²/г & 543 & 359 & 571 \\
Адсорбционная активность по йоду, \% & 71,2 & 51,1 & 84 \\
\hline
\end{tabular}

${ }^{1}$ Образец получен на основе угля-сырца из смешанных древесных отходов лесозаготовок березовой и осиновой древесины. ${ }^{2}$ Образец получен из коры лиственницы сибирской. ${ }^{3}$ Образец получен на основе угля-сырца из древесины осины. 


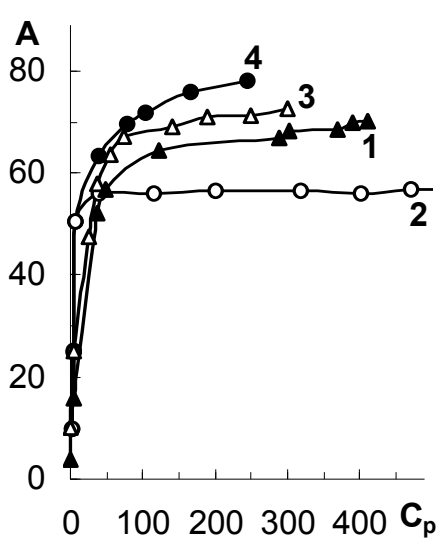

Рис. 1. Изотермы адсорбции палладия (А, мг/г) на углеродных сорбентах: 1 - БОАУ-1; 2 - ЛКАУ-2; 3 - ОСУ-3; 4 - РС; $\mathrm{C}_{\mathrm{p}}$ - равновесная концентрация палладия в растворе, мг/л

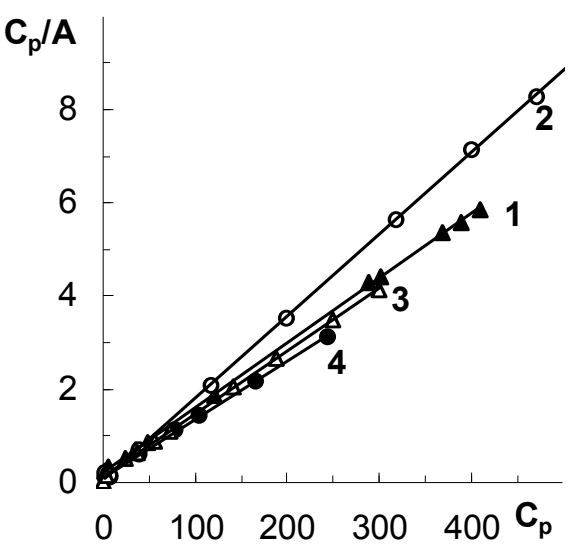

Рис. 2. Выполнимость уравнения Лэнгмюра для адсорбции (А) палладия углеродными сорбентами $\left(\mathrm{C}_{\mathrm{p}}\right.$ - равновесная концентрация палладия в растворе, мг/л; $\mathrm{C}_{\mathrm{p}} / \mathrm{A}$, г/л): 1 - БОАУ-1; 2 - ЛКАУ-2; 3 - OCУ-3; 4 - PC

ных сорбентах, полученных из коры лиственницы сибирской (изотерма 2, образец ЛКАУ-2) и сливовых косточек (изотерма 4, образец РС) при адсорбционной емкости 52-54 мг/г. Однако при равновесной концентрации палладия выше 30-40 мг/л прирост адсорбционной емкости на сорбенте, полученном из коры лиственницы сибирской ЛКАУ-2, резко снижается и не превышает 0,1-0,9 мг/г (0,1-1,5 \% отн.). На промышленном сорбенте PC, а также и на полученных сорбентах БОАУ-1 и ОСУ-3 в вышеуказанном интервале равновесных концентраций прирост адсорбционной емкости составляет не менее 14-18 мг/г.

Приведенные изотермы адсорбции палладия относятся к изотермам I типа по классификации БЭТ - изотерм Лэгмюра [26] и могут быть описаны традиционной теорией мономолекулярной адсорбции. Это свидетельствует о преимущественной адсорбции палладия в микропорах углеродных сорбентов. Выполнимость уравнения Лэнгмюра для адсорбции палладия на углеродных сорбентах подтверждается прямолинейными зависимостями $\mathrm{C}_{\mathrm{p}} / \mathrm{A}-\mathrm{C}_{\mathrm{p}}$, представленными на рис. $2\left(\mathrm{R}^{2}=0,99\right)$. По величине максимальной удельной сорбции палладия (табл. 2), рассчитанной из уравнения Лэнгмюра, сорбенты можно расположить в следующий ряд: ЛКАУ-2 < БОАУ-1 < ОСУ-3 < РС. Следовательно, по значению максимальной сорбционной емкости по палладию наиболее близким к промышленному образцу РС (80,0 мг/г) является углеродный сорбент, полученный из угля-сырца из древесины осины ОСУ-3 (74,1 мг/г).

Большая крутизна изотерм адсорбции свидетельствует о высоком коэффициенте использования емкости сорбентов (табл. 2). Так, при исходной концентрации палладия 400-500 мг/л коэффициент использования емкости полученных сорбентов по палладию составляет 0,670,73. Это при довольно невысоком расходе сорбентов (10 кг/м³) позволяет получить довольно высокую степень извлечения палладия 93-98 \% (рис. 3). Повышение исходной концентрации палладия в растворе больше указанных величин (до 1000 мг/л) хотя и позволяет повысить коэффициент использования емкости сорбентов до 0,97-0,99, но приводит к уменьшению степени

$$
-545-
$$


Таблица 2. Максимальная удельная адсорбция $\left(\mathrm{A}_{\max }\right)$ и степень извлечения $\mathrm{Pd}(\alpha)$ углеродными сорбентами, коэффициент использования их емкости (К)

\begin{tabular}{|c|c|c|c|c|c|c|}
\hline \multirow{2}{*}{ Сорбент } & \multirow{2}{*}{$\mathrm{A}_{\max }$, мг/Г } & \multicolumn{5}{|c|}{ К/ } \\
\cline { 3 - 7 } & & 100 & 250 & 500 & 850 & 1000 \\
\hline БОАУ-1 & 71,9 & $0,05 / 99,1$ & $0,22 / 97,9$ & $0,73 / 92,8$ & $0,95 / 63,7$ & $0,97 / 59,0$ \\
\hline ЛКАУ-2 $^{2}$ & 57,1 & $0,17 / 98,1$ & $0,44 / 97,8$ & $0,88 / 97,5$ & $0,98 / 63,9$ & $0,99 / 53,8$ \\
\hline ОСУ-3 $^{3}$ & 74,1 & $0,14 / 99,6$ & $0,35 / 98,5$ & $0,67 / 95,1$ & $0,98 / 79,8$ & $0,99 / 70,7$ \\
\hline РС $^{4}$ & 80,0 & $0,12 / 98,8$ & $0,31 / 98,7$ & $0,63 / 98,4$ & $0,90 / 87,7$ & $0,96 / 76,1$ \\
\hline
\end{tabular}

${ }^{1}$ Образец получен на основе угля-сырца из смешанных древесных отходов лесозаготовок березовой и осиновой древесины. ${ }^{2}$ Образец получен из коры лиственницы сибирской. ${ }^{3}$ Образец получен на основе угля-сырца из древесины осины. ${ }^{4}$ Промышленный сорбент, полученный из сливовых косточек.

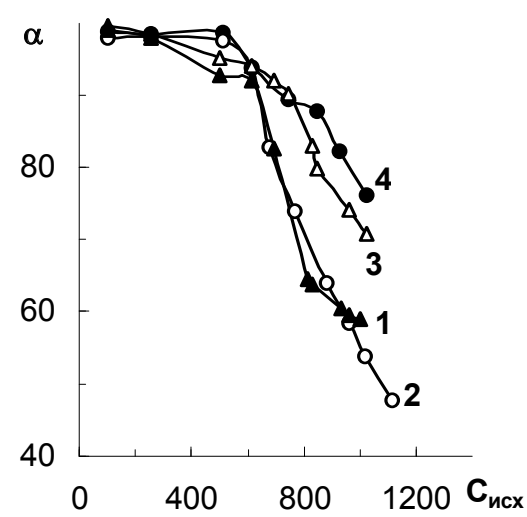

Рис. 3. Зависимость степени извлечения палладия ( $\alpha$, \%) углеродными сорбентами $(1-$ БОАУ-1; 2 ЛКАУ-2; 3 - ОСУ-3; 4 - РС) от исходной концентрации палладия (С

извлечения палладия до 54-71 \%. Это свидетельствует о необходимости проведения извлечения палладия из растворов с концентрацией выше 500 мг/л в несколько стадий (не менее 2), что позволит сохранить высокий коэффициент использования емкости полученных сорбентов (0,90-0,99) при достижении высоких степеней извлечения палладия из водных растворов (не менее 95-99\%).

Полученные углеродные сорбенты отличаются достаточно низкой механической прочностью (50-65 \%). Поэтому их регенерация нецелесообразна, что оправдано из-за их достаточно низкой себестоимости, обусловленной низкой стоимостью исходного сырья. Палладий, извлеченный углеродными сорбентами из водных солянокислых растворов, рекомендуется перерабатывать методами, традиционными для металлургии благородных металлов [1-4].

\section{Выводы}

На углеродных сорбентах, полученных из угля-сырца древесины осины, из смешанных древесных отходов лесозаготовок березовой и осиновой древесины (ветки, сучья, вершинник), а также из коры лиственницы сибирской, достигнута высокая степень извлечения палладия

$$
-546-
$$


(73-99 \%) из солянокислых водных сред в широком интервале концентраций палладия (от 50 до 1000 мг/л).

Максимальную адсорбцию по палладию (71-74 мг/г) имеют углеродные сорбенты, полученные из угля-сырца на основе древесины осины и смешанных древесных отходов лесозаготовок березовой и осиновой древесины. Наиболее высокая степень извлечения палладия 95-99 \% отмечена при невысоком расходе углеродных сорбентов (до 10 кг/м³) и при исходных концентрациях палладия до 400-500 мг/л.

\section{Список литературы}

1. Меретуков М.А., Орлов М.А. Металлургия благородных металлов. Зарубежный опыт. М.: Металлургия, 1990. 416 с. [Meretukov M.A., Orlov M.A. Metallurgy of noble metals. Foreign experience. Moscow: Metallurgy, 1990. 416 p. (In Russ.)]

2. Лолейт С.И., Меретуков М.А., Стрижко Л.С., Гурин К.К. Современные проблемы металлургии и материаловедения благородных металлов. М.: МИСИС, 2012. 196 с. [Loleyt S.I., Meretukov M.A., Strizhko L.S., Gurin C.C. Modern problems of metallurgy and materials' science of noble metals. Moscow: MISIS, 2012, 196 p. (In Russ.)]

3. Вольдман Г.М., Зеликман А.Н. Теория гидрометаллургических процессов. М.: Интермет Инжиниринг, 2003. 464 c. [Vol'dman G.M., Zelikman A.N. Theory of hydrometallurgical processes. Moscow: Intermet Ingineering, 2003, 464 p. (In Russ.)]

4. Букин В.И., Игумнов И.С., Сафонов В.В. Переработка производственных отходов и вторичных сырьевых ресурсов, содержащих редкие, благородные и цветные металлы. М.: ООО «Деловая столица», 2002. 224 с. [Bukin V.I., Igumnov I.S., Safonov V.V. Processing of industrial wastes and recovered raw materials contained rare-earth, noble and non-ferrous metals. Moscow: OOO Delovaja stolitsa, 2002. 224 p. (In Russ.)]

5. Елшин В.В. Теория и практика сорбционного извлечения благородных металлов из растворов и пульп активными углями: автореф. дис. ... д-ра техн. наук. Иркутск, 2000. 38 c. [Elshin V.V. Theory and practice of noble metals sorption from solutions and pulps by active carbons: Abstract of the thesis of the doctor of technical sciences. Irkutsk, 2000. 38 p. (In Russ.)]

6. Дударев В.И. Углеродные адсорбенты для извлечения металлов из растворов и пульп: автореф. дис. ... д-ра техн. наук. М., 2001. 34 с. [Dudarev V.I. Carbon sorbents for metals' sorption from solutions and pulps: Abstract of the thesis of the doctor of technical sciences. Moscow, 2001. 34 p. (In Russ.)]

7. Леонов С.Б., Елшин В.В., Дударев В.И. Углеродные адсорбенты на основе ископаемых углей. Иркутск: ИРГТУ, 2000. 243 с. [Leonov S.B., Elshin V.V., Dudarev V.I. Carbon sorbents at the base of fossil coals. Irkutsk: IrGTU, 2000. 243 p. (In Russ.)]

8. Мухин В.М., Клушин В.Н. Активные угли России. М.: Металлургия, 2000. 352 с. [Mukhin V.M., Klushin V.N. Active carbons of Russia. Moscow: Metallurgy, 2000. 352 p. (In Russ.)]

9. Когановский А.М., Клименко Н.А., Левченко Т.М., Рода И.Г. Адсорбция органических веществ из воды. Л.: Химия, 1990. 256 с. [Koganovsky A.M., Klimenko N.A., Levchenko T.M., Roda I.G. Sorption of organic substances from water. Leningrad: Khimija, 1990. 256 p. (In Russ.)]

10. Мухин В.М. Новый активный уголь. Новые активные угли на основе антрацита // Деловая слава России. Межотраслевой альманах. 2013. № 39. [Mukhin V.M. New active carbon. New

$$
-547-
$$


active carbons at the base of anthracite. Delovaya slava Rossii. Mezhotraslevoy al'manakh 2013. N. 39. (In Russ.)]

11. Мухин В.М., Клушин В.Н. Производство и применение углеродных адсорбентов. М.: РХТУ им. Д.И.Менделеева, 2012. 308 с. [Mukhin V.M., Klushin V.N. Production and application of carbon sorbents. Moscow: RCTU by name of D.I.Mendeleev, 2012. 308 p. (In Russ.)]

12. Кузнецов Б.Н. Синтез и применение углеродных сорбентов // Соросовский образовательный журнал. 1999. № 12. С. 29-34. [Kuznetsov B.N. Synthesis and application of carbon sorbents. Sorosovsky obrazovatel'ney zhurnal 1999. N 12. P. 29-34.]

13. Беседина И.Н., Симкин Ю.Я., Петров В.С. Получение углеродных материалов из отходов сухой окорки лиственницы сибирской. 3. Получение активных углей // Химия растительного сырья. 2002. №2. C. 71-74. [Besedina I.N., Simkin Yu.Ya., Petrov V.S. Production of carbon materials from the waste dry debarking Siberian larch bark. 3. Production of active carbons. Khimija Rastitel'nogo syr'ja 2002. N 2. P. 71-74. (In Russ.)]

14. Кузнецов Б.Н., Головин Ю.Г., Головина В.В. и др. Получение углеродных адсорбентов из продуктов экстракционной переработки коры лиственницы сибирской // Химия растительного сырья. 2002. № 2. C. 57-61. [Kuznetsov B.N., Golovin Yu.G., Golovina V.V. et al. Production of carbon sorbents from extractive debarking Siberian larch bark products. Khimija Rastitel'nogo syr' ja 2002. N 2. P. 57-61. (In Russ.)]

15. Иванов И.П., Судакова И.Г., Иванченко Н.М., Кузнецов Б.Н. Изучение свойств активных углей из зерненой коры лиственницы // Химия растительного сырья. 2011. № 1. С. 81-86. [Ivanov I.P., Sudakova I.G., Ivanchenko N.M., Kuznetsov B.N. Studying of the properties of activated carbons from graining larch bark. Khimija Rastitel'nogo syr' ja 2011. N 1. P. 81-86. (In Russ.)]

16. Еремина А.О., Головина В.В., Угай М.Ю., Рудковский А.В. Углеродные адсорбенты из древесных отходов в процессе очистки фенолсодержащих вод // Химия растительного сырья. 2004. № 2. C. 67-71. [Eremina A.O., Golovina V.V., Ugay M.Yu., Rudkovsky A.V. Carbon sorbents from wood wastes at phenol's contained water purification. Khimija Rastitel'nogo syr'ja 2004. N 2. P. 67-71. (In Russ.)]

17. Еремина А.О., Головина В.В., Угай М.Ю., Рудковский А.В. Активные угли из отходов переработки древесины при очистке сточных вод от поверхностно-активных веществ // Журнал прикладной химии. 2004. Т. 7. Вып. 5. С. 779-782. [Eremina A.O., Golovina V.V., Ugay M.Yu., Rudkovsky A.V. Active carbons from wood wastes at wastewaters purification from surface-active substances. Journal of Applied Chemistry 2004. Vol. 7. Is. 5. P. 779-782. (In Russ.)]

18. Головин Ю.Г., Щипко М.Л., Кузнецов Б.Н. и др. Активация древесного угля в аппаратах кипящего слоя // Химия в интересах устойчивого развития. 1996. Т. 4. № 3. С. 193-199. [Golovin Yu.G., Schipko M.L., Kuznetsov B.N. et al. Activation of charcoal at the fluidized-bed apparatuses. Chemistry for Sustainable Development 1996. Vol. 4. N 3. P. 193-199. (In Russ.)]

19. Патент 2039078 РФ. Петров В.С. Способ термической обработки материалов растительного происхождения и устройство для его осуществления. Опубл. 09.07.95. [Patent 2039078 RU. Petrov V.S. Method of heat treatment of vegetation's raw materials and apparatus for its implementation. Publ. Date 09.07.95. (In Russ.)]

20. Колышкин Д.А. Активные угли: Справочник. Л.: Химия, 1985. 56 с. [Kolyshkin D.A. Active carbons. Handbook. Leningrad: Khimija, 1985. 56 p. (In Russ.)] 
21. Кинле Х., Бадер Э. Активные угли и их промышленное применение. Л.: Химия, 1984. 216 c. [Kinle Kh., Bader A. Active carbons and their commercial application. Leningrad: Khimija, 1984. 216 p. (In Russ.)]

22. Фенелонов В.Б. Пористый углерод. Новосибирск: изд-во ИК СО РАН, 1995. 518 с. [Fenelonov V.B. Porous carbon. Novosibirsk: Publ. House IC SB RAS, 1995. 518 p. (In Russ.)]

23. Фенелонов В.Б. Введение в физическую химию формирования супрамолекулярной структуры адсорбентов и катализаторов. Новосибирск: Изд-во ИК СО РАН, 2002. 414 с. [Fenelonov V.B. The introduction to physical chemistry of supra-molecular structure's forming of sorbents and catalysts. Novosibirsk: Publ. House IC SB RAS, 2002. 414 p. (In Russ.)]

24. Смирнов А.Д. Сорбционная очистка воды. Л.: Химия, 1982. 168 с. [Smirnov A.D. Adsorption treatment of water. Leningrad: Khimija, 1982. 168 c. (In Russ.)]

25. Бимиш Ф. Аналитическая химия благородных металлов. Ч. 2. Под ред. С.И. Гинзбург. М.: Мир, 1969. 400 с. [Bimish F. Analytical chemistry of noble metals. Part 2. Under Ed. Ginzburg S.I. Moscow: Mir, 1969. 400 p. (In Russ.)]

26. Кельцев Н.В. Основы адсорбционной техники. М.: Химия, 1984. 592 с. [Kel’tsev N.V. Background of adsorptive technique. Moscow: Khimija, 1984. 592 p. (In Russ.)] 